\title{
Incidence and perinatal outcome of multiple pregnancy in a tertiary care centre in Central India
}

\author{
Nutan Yadav, Madhuri Alwani*, Ankita Singh \\ Department of Obstetrics and Gynecology, Sri Aurobindo Medical College and PG Institute, Indore, Maharashtra, \\ India
}

Received: 11 March 2018

Accepted: 05 April 2018

*Correspondence:

Dr. Madhuri Alwani,

E-mail: drmadhuri_2007@rediffmail.com

Copyright: (C) the author(s), publisher and licensee Medip Academy. This is an open-access article distributed under the terms of the Creative Commons Attribution Non-Commercial License, which permits unrestricted non-commercial use, distribution, and reproduction in any medium, provided the original work is properly cited.

\section{ABSTRACT}

Background: The incidence of multiple pregnancy is increasing all over the world because of assisted reproductive technology or spontaneously as a result of numerous risk factors. The objective of this study was to study the perinatal outcome of multiple pregnancy in a tertiary care centre in central India

Methods: It is a prospective study total 2289 pregnant woman were enrolled. Out of which 72 pregnant women were either a twin or triplet. 2217 pregnant women were singleton and had acted as controls. Perinatal outcomes including perinatal morbidity and mortality in relation to history regarding any complication in the present pregnancy were noted and analyzed.

Results: In case of multiple pregnancy $90.2 \%$ were conceived between $20-30$ years of age and $9.8 \%$ more than 30 years.13.9\% cases of multiple pregnancy were less than 34 weeks at the time of delivery. The IUGR in multifetal pregnant patient was significantly higher. Oligohydromnios was seen in 3 out of 72 multifetal gestation which accounted for $4.1 \%$. The proportion of singleton and multiple pregnant females who had anemia during pregnancy was $92.33 \%$ and $91.67 \%$. Most common indication of LSCS in multifetal gestation is abnormal presentation during labour accounting for $41.7 \%$ of LSCS. The most common indication for NICU admission in case of multifetal pregnancy was $80.8 \%$.

Conclusions: Majority of the twin pregnancy is high risk one, and as such all twin preganancies should have mandatory hospital delivery. Early diagnosis, antenatal, intra-natal and post-partum cares are necessary to improve the outcome.

Keywords: Central India, Incidence, Multiple pregnancy, Risk factors

\section{INTRODUCTION}

The occurrence of twin and multiple pregnancies has increased in developed countries and is associated with concern in the health care system. ${ }^{1}$ Multiple pregnancy results in premature delivery, lower one-year survival in multiple infants compared to singletons. The frequency of underweight newborns and increased congenital anomalies. In India, up to $1 \%$ of the pregnancies are twin gestation and $10 \%$ of perinatal mortality can be attributed to twin pregnancies, a few studies conducted in India have reported a frequency of twin pregnancy.,3 Inconsistency in reporting the frequency of multiple pregnancy could be due to structural differences in the populations studied and design effect and systematic errors (selection or information bias), in addition to changes in the frequency of the interested outcome over time. ${ }^{4}$ In India, studies on the incidence of twin 
pregnancies and risk factors are very limited. Thus, conducting study to determine the incidence and identify the risk factors is very essential for program improvement.

\section{METHODS}

\section{Study design and setting}

A prospective hospital-based study was carried out in the Department of Obstetrics and Gynecology at a Tertiary level health care referral centre over a period of two year from October 2015 to October 2017. Women in the 2nd trimester of pregnancy who have completed 28 weeks of gestation were included in the study. Findings were analyzed with the biosocial characteristics of the patient and maternal and perinatal outcome. Results were analyzed using percentage and proportion. History regarding age, parity, duration of pregnancy, menstrual history, obstetric history and history regarding any complication in the present pregnancy were noted.

General clinical examination like weight, pulse, blood pressure, presence of pallor, edema, size of the uterus, presentation, adequacy of liquor was taken into consideration. Per-speculum and Per-vaginal examination was done to look for any evidence of rupture of membrane and cervical status.

\section{Data collection and sampling techniques}

The study group that was included in the study was all the multiple pregnancy. A control group of the entire singleton pregnancy was included in the study who has delivered in our institute. Similar confounding factors with respect to age, month of gestation, obstetric formula, associated maternal high-risk factors like PIH, IUGR, PROM, congenital malformations were taken into consideration. The patient was followed up by observing the mode of delivery, and in case of caesarian section the indication was noted. The condition of the babies was assessed as per the birth weight, apgar score (at $1 \mathrm{~min}$ and at 5 min interval) and the need for NICU admission. These babies were followed up till discharge from the Hospital.

\section{Data management and analysis}

The collected data were coded and entered to SPSS for windows version 21.0 for cleaning and analysis. Descriptive statistics (means and proportions) were used to describe the main features of the data. Categorical and continuous variables were summarized as number (\%) and mean (SD). The frequency of multiple pregnancies was calculated as the percentage of multiple pregnancies by mother's age, history of infertility, assisted reproductive technique (ART), history of multiple pregnancy in the mother's family, history of multiple pregnancy in the father's family, the mother born of multiple pregnancy, and the father born of multiple pregnancy. Crude odds ratios (OR)for the association between the selected characteristics (maternal age, economic status, a history and reproductive history) and multiple pregnancy were computed by univariate logistic regression. In the analysis we considered hospitals as a cluster.

\section{RESULTS}

The total pregnant women who had enrolled in our study were 2289. Out of which 72 pregnant women were either a twin or triplet. 2217 no of pregnant ladies were singleton and had acted as controls. Mean age of the study population was $26.08 \pm 4.3$ years, singleton pregnant women were $26.1 \pm 4.4$ years and multifetal pregnant women were $25.9 \pm 4.1$ years. In singleton pregnancy most of them belonged to low socio-economic status. While in case of multiple pregnancy, around $40 \%$ belonged to middle class and $60 \%$ to lower class.

Table 1: Age incidence and distribution of primigravida among multiple and singleton pregnancies.

\begin{tabular}{|c|c|c|c|}
\hline & Single & Multiple & Total \\
\hline \multicolumn{4}{|c|}{ Incidence of age } \\
\hline \multirow{2}{*}{$<20$} & 88 & 0 & 88 \\
\hline & $100.0 \%$ & $0.0 \%$ & $100.0 \%$ \\
\hline \multirow{2}{*}{$20-30$} & 1815 & 65 & 1880 \\
\hline & $96.5 \%$ & $3.5 \%$ & $100.0 \%$ \\
\hline \multirow{2}{*}{$31-40$} & 310 & 7 & 317 \\
\hline & $97.8 \%$ & $2.2 \%$ & $100.0 \%$ \\
\hline \multirow{2}{*}{$>40$} & 4 & 0 & 4 \\
\hline & $100.0 \%$ & $0.0 \%$ & $100.0 \%$ \\
\hline \multicolumn{4}{|c|}{ Age distribution of primigravida } \\
\hline \multirow{2}{*}{$<20$} & 84 & 0 & 88 \\
\hline & $10.0 \%$ & $0.0 \%$ & $100.0 \%$ \\
\hline \multirow{2}{*}{$20-30$} & 698 & 36 & 1880 \\
\hline & $82.7 \%$ & $90.0 \%$ & $100.0 \%$ \\
\hline \multirow{2}{*}{$31-40$} & 62 & 4 & 317 \\
\hline & $7.3 \%$ & $10.0 \%$ & $100.0 \%$ \\
\hline
\end{tabular}

\section{Age-wise distribution}

The 88 women had got pregnant before 20 years of age. Total of 1880 pregnancies were conceived in the age group of 20-30 in the whole study group. A total of 321 had a higher maternal age ( $>31$ years) when they had conceived. A total of $81.86 \%$ of singleton pregnancies and $90.2 \%$ multiple pregnancies were conceived between 20-30 years of age. $14.16 \%$ of singleton pregnant and $9.7 \%$ multiple pregnant women were more than 30 years (Table 1). The mean age of primigravida in singleton was $23.93 \pm 4.1$ years. The mean age of primigravida in multiple was $25.58 \pm 4.5$ years, slightly higher than in case of singleton pregnancy. Among primigravida age in study group $9.5 \%$ were less than 20 years, $83 \%$ of $20-30$ years and $7.5 \%$ were more than 30 years of age. In the singleton pregnant women $10 \%$ were less than 20 yrs of 
age, $82 \%$ belonged in the age group of $20-30$ and $7.3 \%$ were more than $30 \mathrm{yrs}$ of age. In the multifetal pregnant women $90 \%$ belonged in the age group of $20-30,10 \%$ were more than 30 yrs of age, $10 \%$ belonging in the age group of 31-40 was slightly higher than in singleton (7.3\%) pregnancy (Table 1$)$, but not significantly higher.

\section{According to parity}

The $41.5 \%$ of singleton was nullipara.39.6\% of singleton had one child birth before. $18.8 \%$ of singleton had more than one previous birth before. A significant no of multifetal gestational women was nullipara during the study i.e. $62.5 \%$. A $29.2 \%$ of multifetal pregnant women had one birth before. Only $8.3 \%$ of the multifetal pregnant women had given birth more than once.

\section{According to infertility conception}

Out of total 2217 cases of singleton pregnant women 22 had conceived after infertility treatment. 2,195 singletons had conceived spontaneously. Only 3 women with multifetal pregnancy had conceived after taking infertility treatment.69 women with multifetal pregnancies had conceived spontaneously (Table 2).

Table 2: Distribution of singleton and multifetal pregnancy according to parity and infertility conception.

\begin{tabular}{|c|c|c|}
\hline & Single & Multiple \\
\hline \multicolumn{3}{|l|}{ Parity } \\
\hline \multirow{2}{*}{ P 0} & 921 & 45 \\
\hline & $41.5 \%$ & $62.5 \%$ \\
\hline \multirow{2}{*}{ P 1} & 878 & 21 \\
\hline & $39.6 \%$ & $29.2 \%$ \\
\hline \multirow{2}{*}{ P 2-4 } & 417 & 6 \\
\hline & $18.8 \%$ & $8.3 \%$ \\
\hline \multirow{2}{*}{ P 4+ } & 1 & 0 \\
\hline & $0.0 \%$ & $0.0 \%$ \\
\hline \multicolumn{3}{|c|}{ Infertility Conception } \\
\hline \multirow{2}{*}{ Infertility } & 22 & 3 \\
\hline & $1.0 \%$ & $4.2 \%$ \\
\hline \multirow{2}{*}{ Spontanous } & 2195 & 69 \\
\hline & $99.0 \%$ & $95.8 \%$ \\
\hline
\end{tabular}

\section{According to type of placentation in twins}

The rate of monochorionic and monoiniotic twin gestation in among twin was $1.4 \%$, monochorionic and diamniotic twin among twin was $81.2 \%$ and diamonitic and dichorionic twin among twin was $17.4 \%$ (Table 2).

\section{According to preterm delivery}

Overall the incidence of preterm delivery was $14.3 \%$ in the study population. The prevalence of preterm delivery in singleton was $12.8 \%$. $87.2 \%$ of all singleton pregnant women had delivered at term. The $84.7 \%$ of singleton mother had delivered at term. The gestational age of delivery of $12.3 \%$ of singleton was $34-37$ wks. In $3 \%$ of cases of singleton mother gestational age at delivery was extremel preterm i.e. less than 34 wks. $20.8 \%$ of multiple pregnancy women had delivered at term. In case of $65.3 \%$ of multiple pregnancy the gestational age was between $34-37$ at the time of delivery. $13.9 \%$ cases of multiple pregnancy were less than 34 weeks at the time of delivery. Thus, not only is the prevalence of preterm significantly more in multiple, the chances that the preterm will be extremely preterm is significantly higher than in singleton gestation. The next most common complication encountered among singleton preterm was the incidence of PROM accounting for 22.9\%.PIH, severe PIH and eclampsia as a cause of preterm was seen in $25.4 \%$ of all singleton preterm. $24.4 \%$ of all multifetal pregnant females had delivered preterm. PROM resulting in preterm delivery in multifetal gestation was seen in $13.3 \%$ of cases. Thus anemia as co-morbidity was the most prevalent.

\section{According to high risk factors}

Overall the prevalence of PIH in the study group was $10.2 \%$. The proportion of multifetal pregnant women who had developed hypertension after 28 weeks of pregnancy was $37.5 \%$. Women in singleton pregnant group the proportion of women who had PIH during pregnancy was $9.7 \%$.

The proportion of multifetal pregnancy which had IUGR was $20.8 \%$ and $8.3 \%$ of singleton pregnant women had IUGR during pregnancy. Two out of the total 72 cases of multifetal pregnancy had incidence of gestational diabetes mellitus. Whereas the incidence of GDM in singleton pregnancy was 20 out of 2217 controls and $0.9 \%$ of the singleton had GDM during pregnancy. Similarly, the incidence of GDM in multifetal pregnant women was $2.7 \%$ and there was no significant difference between the prevalence of GDM in singleton and multifetal pregnant women in our study.

Oligohydramnios was seen in 3 out of 72 multifetal gestation which accounted for $4.1 \%$. In comparison the proportion of singleton pregnancy which had encountered this complication was 37 out of 2217 accounting for $1.6 \%$ of singleton pregnancy. The proportion of abruption seen among the multifetal pregnant females was $2.7 \%$. The prevalence of same among the singleton pregnant females was $0.2 \%$. Overall the prevalence of congenital anomaly in the study group was $1.1 \% .1 .1 \%$ of all singleton babies had congenital malformation diagnosed ultrasonographical antenatal or after delivery. $96.7 \%$ of all foetuses in singleton pregnant females had vertex presentation at the time of delivery. Presentation of the first fetus in the multifetal pregnancy was vertex in $77.78 \%$ of cases. $3.2 \%$ of singleton pregnant fetuses had presentation a non-vertex presentation. Whereas in case of multifetal pregnancies the non-vertex presentation of the first baby was encountered in $22.22 \%$ of cases. 
Anemia was seen in 66 out of 72 cases of multifetal pregnant female. The proportion of singleton and multiple pregnant females who had anemia during pregnancy was $92.33 \%$ and $91.67 \%$. There was no significant difference between the prevalence of anemia during the pregnancy in case of multiple and in singleton.

\section{Type of fetal presentation (only first fetus of twin or triplet pregnancy)}

61 out of 2217 singleton had breech presentation at the time of delivery. 8 out of 2217 singleton had transverse lie at the time of delivery. The most common non vertex presentation in a case of singleton pregnancy was breech at the time of delivery accounting for $2.7 \%$ of the total singleton. The next common non vertex presentation was transverse lie at the time of delivery accounting for $0.3 \%$ of all singleton. In case of multifetal gestation also 15 out of 72 pregnancies had a breech presentation at the time of delivery. Only in 1 case of multifetal gestation transverse lie was seen at the time of delivery.

Table 4: High risk factors among multiple and singleton pregnancies.

\begin{tabular}{|lll|}
\hline Cause & $\begin{array}{l}\text { Prevalence of } \\
\text { causes of } \\
\text { preterm }\end{array}$ & $\begin{array}{l}\text { Distribution } \\
\text { of causes of } \\
\text { preterm }\end{array}$ \\
\hline Anemia & $271(95.8)$ & $43(95.6)$ \\
\hline PIH & $42(14.8)$ & $16(35.6)$ \\
\hline $\begin{array}{l}\text { Severe PIH and } \\
\text { eclampsia }\end{array}$ & $30(10.6)$ & $3(6.7)$ \\
\hline PROM & $65(22.9)$ & $6(13.3)$ \\
\hline IUGR & $34(12)$ & $11(24.4)$ \\
\hline $\begin{array}{l}\text { Ante partum } \\
\text { Hemorrhage } \\
\text { (Placenta Previa } \\
\text { and Abruption) }\end{array}$ & $11(3.9)$ & $4(8.9)$ \\
\hline $\begin{array}{l}\text { Severe } \\
\text { oligohydromnios }\end{array}$ & $6(2.1)$ & - \\
\hline $\begin{array}{l}\text { Abnormal } \\
\text { presentation } \\
\text { (breech and } \\
\text { transverse) }\end{array}$ & $15(5.3)$ & $10(22.2)$ \\
\hline \begin{tabular}{l} 
Cong anomaly \\
\hline
\end{tabular} & $2(0.7)$ & - \\
\hline
\end{tabular}

\section{According to mode of delivery}

Out of 2217 singleton 1655 had a spontaneous or induced vaginal delivery accounting for $74.7 \%$ of all singletons. 11 females in singleton had undergone instrumental delivery either by the use of forceps or vacuum i.e. $0.4 \%$.The rate of LSCS in case of singleton was $24.9 \%$.In multiple there was equal distribution of delivery by vaginal route or by LSCS.50\% of all multiple had a spontaneous vaginal delivery.50\% of all multiple had undergone LSCS at the time of delivery. The most common indication for LSCS in case of singleton was the presence of previous 2 or more LSCS. Most common indication of LSCS in multifetal gestation is abnormal presentation during labour accounting for $41.7 \%$ of LSCS.

Table 5: Type of fetal presentation and mode of delivery among multiple and singleton pregnancies.

\begin{tabular}{|c|c|c|}
\hline & Single & Multiple \\
\hline \multicolumn{3}{|c|}{ Fetal presentation } \\
\hline Breech & $61(2.75)$ & $15(20.8)$ \\
\hline Face & $1(0.05)$ & 0 \\
\hline Footing & $2(0.09)$ & 0 \\
\hline Hand & $1(0.05)$ & 0 \\
\hline Transverse & $8(0.36)$ & $1(1.4)$ \\
\hline Vertex & $2144(96.71)$ & $56(77.8)$ \\
\hline \multicolumn{3}{|c|}{ Mode of delivery } \\
\hline Vaginal & $1655(74.7)$ & $36(50)$ \\
\hline Instrumental & $11(0.4)$ & 0 \\
\hline LSCS & $551(24.9)$ & $36(50)$ \\
\hline
\end{tabular}

\section{Perinatal outcome}

The 2217 femles in singleton pregnant women had given birth to live baby. 142 out of the total 147 babies in multiple pregnant females were born live. The mean birth weight in singleton was $2.72 \pm 0.611 \mathrm{Kg}$. The mean birth weight of babies of multifetal pregnant females was $1.93 \pm 0.469 \mathrm{Kgs}$. The low birth weight among the multiple was due to the increased incidence of preterm delivery. The mean gestational age of multiple at the time of delivery was $35.82 \pm 2.125$ weeks at the time of delivery.

\section{APGAR score}

Out of the 142 number of babies of multifetal pregnant female 17 babies had a low APGAR score of less than 7 accounting for $12 \%$ of cases. Similarly, 84 babies among the 2167 delivered butt singleton pregnant female had low APGAR score less than 7 accounting for $3.9 \%$. APGAR at 5 minute is a better indicator of neonatal outcome. Among the babies of multiple pregnancy, the proportion babies with low APGAR score has decreased from $12 \%$ to $4.9 \%$ In the same manner there is a marked decrease in the proportion of babies with low APGAR score among the singleton babies, which is a positive sign of better neonatal outcome.

\section{Birth weight}

$2 \%$ of multifetal pregnant females gave birth to babies less than $1000 \mathrm{gms}$ as compared to $0.3 \%$ in singleton. $18.7 \%$ of singleton had given birth to babies who were 1500 to $2499 \mathrm{gms}$ as compared to $71.4 \%$ in case of multiple pregnant females. $76.3 \%$ of singleton had a birth weight of 2500 to $3499 \mathrm{gms}$ compared to $13.6 \%$ in case of multiple pregnant females. $2.6 \%$ of singleton delivered a baby whose birth weight was more than $3500 \mathrm{gm}$. The mean gestational age of singleton at the time of delivery was $38.46 \pm 1.938$ weeks at the time of delivery which had 
resulted in a positive prevalence of $76.3 \%$ of singleton having a birth weight between 2500-3499 gm which is significantly higher than in multiple pregnant females i.e. $13.6 \%$. Thus, there is an increase prevalence of low birth weight among multiple than in singleton.

\section{Need for NICU admission}

Most common reasons for NICU admission in cases of singleton pregnancy was low birth weight accounting for $47.7 \%$ of all admission. The next most common reasons for NICU admission is birth asphyxia. The most common indication for NICU admission in case of multifetal pregnancy was $80.8 \%$. The next most common cause for NICU admission was birth asphyxia. The most common cause of neonatal death among singleton was respiratory distress syndrome. The next most common cause of neonatal death was septicemia. The respiratory distress syndrome and septicemia accounted for most causes of neonatal death among multiple. Most of these neonates also had very low birth weight during the delivery.).

\section{DISCUSSION}

Multiple pregnancies are an event that occurs with increased frequency with the increased use of newer assisted reproductive techniques. However multifetal pregnancies are associated with significantly higher morbidity and mortality than are singleton pregnancies.

Monochorionic (MC) twins have a 3-10-fold higher perinatal mortality and morbidity than dichorionic twins.5 A total of 2289 pregnant women had delivered during our study period. The incidence of preterm delivery in our study was $62.5 \%$ as compared to the incidence of $12.8 \%$ seen in singleton gestation. Out of the 72 multifetal pregnant females in our study 45 had delivered preterm accounting for $62.5 \%$. In the study conducted by Obiechina $\mathrm{N}$ et al and Akaba GO et al the incidence of preterm delivery was $36 \%$ and $38.7 \%$ respectively. ${ }^{6,7}$ Chowdhury et al the incidence of preterm delivery was $44.5 \% .^{8}$ The rate of preterm delivery seen in a study done by Blondel B et al in European countries participating in the Peristat project had ranged between 46.3-62.2\%. ${ }^{9}$

In a 2 year observational study conducted by Naushaba et al the prevalence of pregnancy induced hypertension was seen in $31.4 \%$ of all multifetal pregnant women.10 In a retrospective observational analysis of 100 twin pregnancies done by Shagufta et al the incidence of PIH was seen in 28 pregnant women with multifetal gestation. ${ }^{11}$ In a retrospective study of twin deliveries over a period of 10 years Akaba GO et al came across $28 \%$ of pregnant women with multifetal gestation whose pregnancy was complicated by the presence of PIH. ${ }^{7}$ Qazi $\mathrm{G}$ also observed an incidence of $30 \% \mathrm{PIH}$ in multifetal gestation. ${ }^{12}$ A case-control study conducted by Nathan et al had shown that the incidence of IUGR was $47 \%$ and birth weight was less than $10^{\text {th }}$ percentile for the gestational age. ${ }^{13}$ An observational study done by Bangal et al had an incidence of $33.33 \%$ of multifetal pregnant females with IUGR. ${ }^{14}$ But in a retrospective observational analysis of 100 twin pregnancies by Shagufta et al the incidence of IUGR among multifetal gestation was $10 \% .{ }^{11}$ The reason for the same could be due to the small number of sample size in the study group. In the present study we found that the incidence of IUGR among multifetal pregnant females was $20.8 \%$.

Oligohydromnios is a condition in pregnancy characterized by a deficiency of amniotic fluid. The incidence of oligohdromnios in case of multifetal gestation was $4.1 \%$. A study conducted by Chaudhary et al reported an incidence of $5.7 \%$ of polyhydromnios in the twin gestation. ${ }^{8}$ Similarly a study conducted by Bangal et al reported in incidence of $12 \%$ of polyhydromnios in multifetal gestation. ${ }^{14}$ The presence of placenta previa and abruption Placenta was seen in 5.6\% of the total multifetal gestation. In on observational study conductd by the Chaudhary et al the incidence of ant partum haemorrhage was seen in $5.7 \%$ of cases.8 In a similar type of study design done by Bangal et al. whereas the incidence of congenital anomaly in singleton pregnant women was 23 out of 2217 deliveries bringing the rate to 103 per 10,000 births. ${ }^{14}$ Glinianaia et al had shown that rate of congenital anomalies in twins was 405.8 per 10,000 twins versus 238.2 per 10,000 singletons [rate ratios $(\mathrm{RR})=1.7,95 \%$ confidence interval (CI) $1.5-2.0] .{ }^{15}$

According to the retrospective observational study done by Sheela et al the incidence of mal presentation was seen in $35 \%$ of multifetal gestation. ${ }^{16}$ Similar higher incidence was seen in retrospective study of twin deliveries in the hospital over a period of 10 years by Akaba GO et al. ${ }^{7}$ In a retrospective observational analysis of 100 twin pregnancies by Shagufta et al the incidence of malpresentation was seen in $30 \%$ of cases. ${ }^{11}$ In the present study the incidence of malpresentation was seen in $22.22 \%$ of cases of multifetal gestation as compared to $3.2 \%$ in singleton.

Nutritional anaemia is the most prevalent medical complication in both singleton and multiple Chowdhury et al found the prevalence of anemia in $35.8 \%$ of multifetal pregnant females. ${ }^{8}$ Bangal et al In a retrospective observational study of 100 multifetal pregnant women by Shugufta et al the prevalence of anemia was seen in $63 \%$ of all pregnant females. ${ }^{11,14}$ In our study the prevalace of anemia was $91.6 \%$ of all multifetal pregnant females.

A retrospective observational analysis of 100 twin pregnancies by Shugufta et al $60 \%$ of all multifetal pregnant female had undergone LSCS. $^{11}$ In a crosssectional observational study by Chowdhury et al the rate of LSCS was seen as $42 \% .^{8}$ In a retrospective study of twin deliveries in the hospital over a period of 10 years by Akaba GO et al the rate of LSCS was $27.3 \% .^{7}$ In a 
retrospective study in rural village by Sheela et al the rate of LSCS was $40.3 \%$ of all multifetal gestation. ${ }^{16}$ The mean birth weight in singleton was $2.72 \pm 0.611 \mathrm{Kg}$. The mean birth weight of babies of multifetal pregnant females was $1.93 \pm 0.469 \mathrm{Kg}$. The mean gestational age of singleton at the time of delivery was $38.46 \pm 1.938$ weeks at the time of delivery. The incidence of low birth weight was seen in $86.3 \%$ of babies of multifetal gestation. In contrast only $21.1 \%$ of babies in singleton gestation were less than $2500 \mathrm{gm}$ at the time of delivery. The mean gestational age of multiple at the time of delivery was $35.82 \pm 2.125$ weeks at the time of delivery. NICU admission was required in 205 cases of singleton gestation accounting for $9.4 \%$ of all live born babies in singleton pregnancies. The reason for NICU admission in case of multifetal pregnancies was most commonly due to LBW accounting for $80.8 \%$ of cases.

\section{CONCLUSION}

Multiple pregnancies stand further risks for both mother and baby. Though these risks are partly preventable, difficulty in timely recognition of multiple pregnancies at an early date is a main obstacle. Diagnosis of twin pregnancy and determination of chorionicity is essential to anticipate abnormalities of monochorionicity. Antenatal care, with increased rest and nutritional supplementation, early detection of foetal and maternal complications together with thorough intranatal and postnatal vigilance, has much to its credit in lowering both maternal and foetal dangers. Based on the present study results, frequency of multiple pregnancy in older women, women with history of ART, and a history of multiple pregnancy in the mother's family had a significant relationship with increased frequency of multiple pregnancy. LBW mainly due to preterm labour and intra uterine growth retardation were the most important factors responsible for the neonatal deaths. The perinatal mortality could be reduced considerably if we can achieve birth weight. Thus, proper antenatal care, planned delivery and better facilities for care of premature babies can bring about a reduction in perinatal mortality of twin pregnancies.

\section{Funding: No funding sources}

Conflict of interest: None declared

Ethical approval: The study was approved by the Institutional Ethics Committee

\section{REFERENCES}

1. Collins J. Global epidemiology of multiple birth. Reprod Biomed Online. 2007;15(3):45-52.

2. The Eshrecapri Workshop Group. Multiple gestation pregnancy. Hum Reprod. 2000;15(8):1856-64.
3. Daltveitak, Vollset SE, Skjærven R, Irgens LM. Impact of multiple births and elective deliveries on the trends in low birth weight in norway, 1967-1995. Am J Epidemiol. 1999;149(12):1128-33.

4. Pasquini L, Wimalasundera RC, Fisk NM. Management of other complications specific to monochorionic twin pregnancies. Best Pract Res Clin Obstet Gynaecol. 2004;1:577-99.

5. Smits J, Monden C. Twinning across the developing world. Plos One. 2011;6(9):e25239.

6. Obiechina N, Okolie V, Eleje G, Okechukwu Z, Anemeje O. Twin versus singleton pregnancies: the incidence, pregnancy complications, and obstetric outcomes in a nigerian tertiary hospital. Int $\mathbf{J}$ Women's Health. 2011;3:227-30.

7. Akaba Go, Agidate, Onafowokan O, Offiongra, Adewolend. Review of twin pregnancies in a tertiary hospital in Abuja, Nigeria. J Health Population Nutr. 2013;31(2):272-7.

8. Chowdhury S, Hussainma. Maternal complications in twin pregnancies. Mymensingh Med J. 2011;20(1):83-7

9. Blondel B, Macfarlane A, Gissler M, Breart G, Zeitlin J. Preterm birth and multiple pregnancy in european countries participating in the peristat project. BJOG, 2006;113:528-35.

10. Naushaba. Maternal morbidity and perinatal outcome with twin pregnancy. J Ayub Med Coll Abbottabad 2010;22(2):251-6.

11. Shugufta y $\mathrm{r}(\mathrm{md})$, rizwana $\mathrm{h}(\mathrm{md})$, preeti s (mbbs) studying pregnancy outcome in twin gestation in developing world.Jdms. 2014;13(5):62-65

12. Gulrukhqazi. Obstetric and perinatal outcome of multiple pregnancy. J Coll Phy Surg Pak. 2011;21(3):142-5.

13. Fox NS, Rebarber A, Klauser CK, Roman AS, Saltzman DH. Intrauterine growth restriction in twin pregnancies: incidence and associated risk factors. Thieme Med Publishers Am J Perinatol. 2011;28(4):267-72.

14. Bangal VB, Patel SM, Khairnar DN. Study of maternal and fetal outcome in twin gestation at tertiary care teaching hospital. IJBAR. 2012;3(10):758-62.

15. Glinianaiasv, Rankin J, Wright C. Congenital anomalies in twins: a register-based study. Hum Reprod. 2008;23(6):1306-11.

16. Sheela SR, Patila A. A study of maternal and fetal outcome in multifetal gestation at a rural based teaching hospital - a retrospective analysis. Int J Biol Med Res. 2014;5(2):3994-7.

Cite this article as: Yadav N, Alwani M, Singh A. Incidence and perinatal outcome of multiple pregnancy in a tertiary care centre in Central India. Int J Reprod Contracept Obstet Gynecol 2018;7:1912-7. 